\title{
EL DERECHO AL HONOR, LA HONRA Y BUENA REPUTACIÓN: ANTECEDENTES Y REGULACIÓN CONSTITUCIONAL EN EL ECUADOR
}

THE RIGHT TO HONOR, IMAGE AND GOOD REPUTATION: HISTORICAL BACKGROUND AND CONSTITUTIONAL REGULATION IN ECUADOR

\section{Darío Echeverría Muñoz ${ }^{*}$}

Resumen: El presente trabajo de investigación tiene como objetivo analizar el Derecho al honor, la honra y buena reputación que tiene toda persona a su favor, consagrado en el Artículo 66, numeral 18 de la Constitución de la República del Ecuador. Se revisarán sus raíces históricas occidentales para posteriormente hacer un estudio comparado desde su primera regulación normativa hasta la actualidad, atendiendo a las constituciones que han estado vigentes y a cómo este derecho ha evolucionado a lo largo de la historia nacional. Además, se realizará un breve análisis a la jurisprudencia nacional para determinar los alcances y delimitaciones que posee este derecho para su debido resguardo, así como también sus mecanismos de protección en caso de ser irrespetado. Este ensayo jurídico se compone de cuatro partes: antecedentes históricos, regulación constitucional, jurisprudencia y finalmente sus conclusiones. En ellas se constata como este derecho guarda relación con la dignidad humana, cuya noción es el punto de partida fundamental para que fuese reconocido dentro de las constituciones modernas y para la previsión de mecanismos efectivos para su tutela efectiva. Se observa además cómo la libertad personal termina donde inicia la del resto de nuestros semejantes.

\footnotetext{
* Abogado con estudios de posgrado en Derecho Internacional y Negocios en ESADE Law School, especializado en Derecho Financiero, Bursátil y de Seguros en la Universidad Andina Simón Bolívar (Quito, Ecuador), con experiencia dentro de los sectores público y privado en la prestación de servicios jurídicos. darioecmunoz@ outlook.com
} 
Palabras clave: Honor, honra, buena reputación, Derecho Constitucional, Derechos Humanos

Abstract: The purpose of this article is to analyze the right of honor, image, and good reputation that everyone has in their favor, established in Article 66, number 18 of the Ecuadorian Constitution. There will be a revision of its western historical roots and, subsequently, a comparative study from its first normative regulation to the present day based on the constitutions that have been in force and how this right evolved throughout its national legal history. Besides, a brief analysis of national jurisprudence will be considered to determine its scopes and delimitations, as well as its protection mechanism if it has been disrespected. This legal essay consists of four parts: historical background, constitutional regulation, jurisprudence, and finally its conclusions. The conclusions show how this right is related to human dignity, whose concept is the fundamental starting point for it to be recognized worldwide within modern constitutions leading to concrete mechanisms for its effective guardianship. It also reminds us that personal freedom ends where the rest of our fellow men begin.

Keywords: Honor, Image, Good Reputation, Constitutional Rights, Human Rights

Sumario. I. Antecedentes históricos. II. Regulación constitucional. III. Jurisprudencia. IV. Conclusiones. Referencias.

\section{ANTECEDENTES HISTÓRICOS}

Hablar del derecho al honor, la honra y buena reputación como parte de los derechos humanos que son fundamentales para la vida del ser humano conlleva prácticamente a remitirnos a la historia humana desde sus inicios, pero recién desde hace 200 años, es cuando ya no solamente se menciona a estos derechos, también se los cita y obtienen la fuerza jurídica necesaria para salvaguardar los intereses de las personas dentro de la sociedad.

Para entender lo que es el honor y la honra en el ámbito jurídico, es necesario citar sus definiciones. Sobre la honra Cabanellas (2003, p. 206) nos dice que es un «vocablo con diversas acepciones, entre ellas: estima y respeto de la dignidad propia. | Buena opinión y fama adquirida por la virtud | Pudor, honestidad y recato de las mujeres». Confróntese lo dicho con lo que dice Ossorio (2004): 
«Honor: cualidad moral que nos lleva al más severo cumplimiento de nuestros deberes respecto del prójimo y de nosotros mismos. | Gloria o buena reputación que sigue a la virtud, al mérito o a las acciones heroicas, la cual trasciende a las familias, personas y acciones mismas del que se la granjea."

Honra: vocablo con diversas acepciones, entre ellas: Estima y respeto de la dignidad propia. | Buena opinión y fama adquirida por la virtud y el mérito. | Pudor, honestidad y recato de las mujeres» (p. 462).

Ambos autores coinciden con la definición de lo que es la honra. Si bien en la actualidad ambas palabras son consideradas como sinónimos, sus efectos para la aplicación son totalmente distintos, para ello es necesario recurrir a su origen etimológico como punto de partida. La palabra honor procede del griego ainos y significa alabanza, halago; esta característica poseía una fuerte implicación social. Mientras que el honor en latín proviene de las palabras honor, honoris cuyo significado es de rectitud, decencia, dignidad, fama, respeto, etc. Cualidades necesarias que las personas debían poseer para ejercer actividades públicas.

En cuanto a la honra, su origen etimológico proviene de la palabra honorare y significa la demostración de afecto que una persona hacía a otra en razón de sus virtudes o méritos. Esto implica que ambos términos deben distinguirse de manera diferente, ya que el honor es una cualidad general, que otorga buena fama o reputación que una persona tiene en base a sus aportes y méritos en la sociedad, mientras que la honra tiene un carácter subjetivo, ya que se relaciona con las virtudes que el ser humano posee y con las cuales actúa frente a una colectividad.

En las sociedades antiguas, este concepto se encontraba arraigado al modo de vida que el ser humano tenía con sus semejantes. Una persona honorable era alguien que practicaba la virtud y el respeto como miembro de la comunidad de la cual era partícipe.

Conviene analizar lo que implicaba el honor históricamente, en la Roma antigua, civilización de la cual deriva gran parte del derecho positivo occidental y cuya influencia se mantiene hasta la actualidad.

El derecho romano es relevante para el estudio y análisis histórico ya que varios tratadistas están de acuerdo que su ordenamiento jurídico fue muy importante y constituye la base para el desarrollo del derecho en los sistemas legales de occidente. Según Mena Villamar (2001, p.165), cuatro características destacan la importancia del derecho romano: (i) su territorialidad, en cuanto era dictado en consideración al territorio y no a las personas; (ii) ser notoriamente individualista, pues protege derechos inherentes al individuo, a la persona; desconoce el derecho social o colectivo que aún no aparecía; (iii) es más de corte civilista, menos penalista; y, (iv) su marcado carácter privado, y poco desarrollo de lo público. Estas 
características se reflejan en la sociedad romana durante el desarrollo de su sistema jurídico, y se constatan en las diversas relaciones entre semejantes, entre ellas las relacionadas con el honor.

Cualquier persona que pertenece a una generalidad, posee una estimación social, que en el derecho romano se conocía como existimatio, un honor civil que influía en el ejercicio de derechos. Esta institución jurídica romana confería a la persona el derecho a no ser objeto de opiniones perjudiciales a su autoestima o reputación social, ya que si este era vulnerado con la debida demostración, era una causal grave para alterar la capacidad jurídica que tenía la persona.

Sin embargo, la existimatio confería una protección a la persona en caso de que esta fuera objeto de ataques por actos ilícitos ajenos que frente a manifestaciones o imputaciones que, en cada momento y lugar, puedan suponer descrédito o menosprecio y, por tanto, desmerecer su condición frente a la sociedad, por lo que esta institución jurídica estaba muy ligada a otra de fundamental importancia, el ius honorum que en Roma era el derecho a participar en cargos públicos.

Con la expedición de la Ley de las XII Tablas aparece la figura de la injuria, la cual consistía una grave ofensa contra el honor, y merecía una severa represión penal. Por otra parte, existía la institución de la infamia que según el autor Alfredo DiPietro (2012, p. 82):

«era la forma de hacer perder a un ciudadano romano su honor civil de tal modo que se le modificaba gravemente su capacidad, puesto que se le impedía el acceso a las magistraturas, el poder votar en los comicios y también el poder actuar en juicio en lugar de otro».

Así pues, para estas instituciones que regulaban el honor de los ciudadanos en Roma, no les era tan simple de amparar, porque para ser personas virtuosas debía comprobarse dicha calidad, ya que en caso de haber cometido un acto que vaya en contra de la sociedad podían perder este derecho, al respecto de esto el mismo autor señala que existían tres tipos de infamia: (i) infamia censoria: en la cual el censor se encargaba de cuidar las buenas costumbres de la sociedad y este tachaba de infame al ciudadano indigno que iba contra ellas; (ii) infamia consularis: aquella en la que, quien presidia los comicios como es el caso del cónsul, rechazaba la pretensión de elegibilidad de un candidato por carecer de honor necesario para el ejercicio de cargos públicos; y, (iii) infamia praetoriana: aquella que impedía actuar a una persona a nombre de otra persona.

Ya en la época de Justiniano se establece una lista de infames. Ahí están los que ejercen oficios deshonestos como el artista de teatro o ser 
gladiador; quienes ofenden a la moral o buenas costumbres, tales como el bígamo, la viuda que contrajera nupcias antes de cumplido el año de su disuelto matrimonio; el condenado por prevaricato y calumnia o el que violó la confianza depositada en contratos regidos por la buena fe (bona fides), tales como comodato, depósito, sociedad, etc. La sociedad romana antigua tomaba muy en serio la reputación que un ciudadano debía tener, ya que, al ser parte de una sociedad; este no podía irrespetar a la misma ni tampoco comportarse de tal manera que pudiera atentar contra los intereses del resto de ciudadanos, y más aún si sus actos tenían implicaciones de tipo político, ya que una sociedad ordenada, conllevaba a que está mantenga su organización y la convivencia entre sus semejantes. Los romanos tenían un alto sentido del honor en las relaciones sociales y jurídicas.

Avanzando un poco más en la historia, en la Edad Media, el honor toma otro matiz, ya que la civilización occidental estaba regida por el cristianismo y por lo tanto la religión tomó un matiz importante en las relaciones sociales, pero entre los cambios que se dieron en relación con los romanos, éste era considerado como un patrimonio exclusivo de las clases nobles, que, en la mayoría de los casos, solucionaban sus diferencias por la vía del duelo; los intentos de la Iglesia por controlar tales ímpetus caballerescos fueron en vano.

En el medioevo, la institución del duelo se instauró justamente para que las personas injuriadas tengan una solución valida a su favor para reparar cualquier ofensa contra su honor y siempre que esté amparada por la ley en ese entonces, dejando en manos de la persona ofendida, la facultad de reparar la afrenta. Esto debía llevarse a cabo siguiendo numerosas reglas para que tenga validez legal lo que de otra forma sería un puro y simple asesinato. Son de esta época los respetados caballeros, quienes tenían un código y se guiaban por valores esenciales como la valentía, los deberes hacia Dios y la sociedad, la fidelidad por cada compromiso contraído libremente. Estas personas defendían al cristianismo que estaba en auge, además de los débiles e indefensos, auxiliaban a los pobres y eran leales a un ideal de virtud. El símbolo de honor para estos caballeros se representaba en la espada.

Son de aquella época las historias de Don Quijote de la Mancha, quien decía a Sancho Panza que por el honor valía la pena aventurar la vida. También el Mío Cid Campeador en sus hazañas buscaba recuperar la honra de su padre, la que fue injustamente arrebatada y que se llevaba consigo hasta sus ganas de vivir.

Pero el honor no era privativo solamente de los caballeros, ya que este atributo se les concedía a los artistas de prestigio y los constructores de las catedrales, en razón de su oficio. Eran usuales por ese entonces las justas y lances caballerescos, donde se producía la confrontación por distintos 
motivos subjetivos, pero en el fondo, la causa era siempre la defensa del honor propio o ajeno. En tanto que por su índole se consideraban excluidos a los siervos de la gleba.

Este comportamiento pervivió en la Edad Moderna. Si bien con la llegada del Renacimiento el humanismo fue el tema central de la época, en la cual de a poco la religión se separaba paulatinamente del poder estatal y los avances científicos tuvieron su resurgimiento para ser profundizado, la imagen de las personas aún seguía considerándose como un derecho inalienable que nadie tenía la atribución de agredir sin sufrir consecuencias. Sin embargo, el derecho al honor estaba especialmente arraigado a la nobleza: era inseparable de esta clase social porque al pertenecer los nobles a un alto estamento, estaban obligados a un comportamiento adecuado a su clase. Privilegio y distinción estaban asociados. La esencia del honor se resumía en una frase bien conocida durante el siglo XVII: "soy quien soy". El honor sirvió a la nobleza para preservar su identidad; fue un factor de integración en la sociedad y de mantenimiento del orden jerárquico.

Centrándonos brevemente en el Ecuador, dentro de este periodo tuvo auge la colonización de los pueblos indígenas por parte del Virreinato de España, y dada la divergencia entre clases sociales existentes correspondientes a su momento histórico, la concepción del honor como distinción social tenía como factor la ascendencia, es así que los españoles o blancos, sean estos criollos o chapetones eran vistos como personas de «raza pura», considerándose deshonrosa las mezclas de razas o aquellas que tengan descendencia indígena, mestiza, negra o mulata.

El historiador Christian Büschges (1997, p. 71) muestra cómo se configuraba el honor en la época colonial de la Real Audiencia de Quito:

«Todos los mencionados rasgos del honor, es decir la «dimensión objetiva» o «material» de este concepto, se imponían como valores sociales, de una manera más bien informal, a través de la fama pública, o sea la reputación. Esta dimensión central del concepto del honor se manifiesta en la documentación estudiada en la gran cantidad de expresiones como "conceptuado", "conocido", "tenido" o "reputado por..." (tal posición, calidad). La particular reputación de las "personas honradas" se expresaba en su derecho o su reclamación de ser tratados con el distintivo de "Don", de gozar de "estimaciones y aprecios" en "actos privados y públicos". Esta reputación se refería sobre todo a "los honores que gozan los nobles". La "plebe", en cambio, se consideraba "despreciable", caracterizada de «desdoro", siempre en el centro de la "infamia pública"».

La época muestra la notable influencia europea en la civilización del nuevo continente. El honor sirve para definir cuestiones de imagen y reputación de una persona. Por otro lado, existía el sesgo entre clases sociales, el "linaje familiar" transmitido por generaciones, mientras el honor 
se limitaba específicamente a la esfera privada como una virtud destacada propiamente de la nobleza. El honor sirvió a la nobleza para preservar su identidad; fue un factor de integración en la sociedad y de mantenimiento del orden jerárquico.

En la edad contemporánea los estudios de varios pensadores e ilustres influenciaron en un gran cambio para derrocar al régimen monárquico y el concentramiento del poder en una sola persona, a fin de que haya una mayor participación de los ciudadanos. Como se sabe, en esto jugó un papel importante la Revolución Francesa de 1789.

Sobre el concepto de honor y su manipulación hecha por la clase noble, el clero y los monarcas, en El Espíritu de las Leyes Montesquieu (1906, p. 45) escribe:

«El honor no es el principio de los estados despóticos.

No es el honor el principio de los Estados despóticos; siendo en ellos todos los hombres iguales, no pueden ser preferidos los unos a los otros; siendo todos esclavos, no hay para ninguno distinción posible.

Además, como el honor tiene sus leyes y sus reglas, y no puede someterse ni doblegarse; como no depende de nadie ni de nada más que de sí mismo, no puede existir conjuntamente con la arbitrariedad, sino solamente en los Estados que tienen constitución conocida y leyes fijas.

¿Cómo podría soportar el déspota? El honor hace gala de despreciar la vida, y el déspota sólo es fuerte porque la puede quitar; el honor tiene reglas constantes y sostenidas, y el déspota no tiene regla ninguna; sus mudables caprichos destruyen toda voluntad ajena.

El honor, desconocido en los Estados despóticos, en los que a veces no hay palabra para expresarlo, reina en las monarquías bien organizadas, en las que da vida a todo el cuerpo político, a las leyes y aún a las virtudes».

Esta afirmación fue una de las bases necesarias para la caída de la monarquía absolutista que existía en Francia. Montesquieu resalta que en un Estado despótico no existe el honor. Según lo antes visto, en las sociedades antiguas estaban estrechamente ligados el honor, la moral y las buenas costumbres; quienes se aprovechaban de otros en razón de su poder o posición, carecían de esto y era necesario instaurarla para todos en igualdad de condiciones.

La caída del monarca francés Luís XVI, además de la toma de la Bastilla, marcó el final de la época en que la nobleza y la iglesia tenían privilegios por sobre el resto de personas. Se conformó luego la Asamblea Nacional Constituyente, la cual expidió la famosa Declaración de los Derechos del Hombre y el Ciudadano (1789). Aunque no se cita ahí expresamente al honor, se declara como derecho «la libre comunicación de pensamientos y opiniones», eso sí, «siempre y cuando responda del abuso 
de esta libertad en los casos determinados por la Ley» (art. 11) Esta disposición declarativa es bien importante en la época en que fue redactada, porque si bien brindaba la libertad para opinar libremente sobre cualquier tema, asimismo otorgaba la responsabilidad hacia la persona que lo emitía en caso de abuso, con lo cual se buscaba respaldar el honor, la honra y aquí por primera vez se puede hablar de la buena reputación que gozan las personas además de nacer libres e iguales ante la ley.

Pasarán varios años hasta que este derecho sea consagrado de manera definitiva en la legislación interna de cada país y sea aplicable de forma adecuada en su esencia y naturaleza. La Segunda Guerra Mundial, donde se dio el mayor genocidio que la historia ha registrado y donde millones de soldados perdieron la vida, fue el detonante principal para la expedición de la Declaración Universal de Derechos Humanos (1948). Este documento ratificado por el Ecuador, dice que nadie será objeto «de injerencias arbitrarias en su vida privada, su familia, su domicilio o su correspondencia, ni de ataques a su honra o a su reputación. Toda persona tiene derecho a la protección de la ley contra tales injerencias o ataques». Todos los estados miembros de la ONU deben respetar y hacer respetar los derechos humanos; en el caso de lo honor, la honra y buena reputación, además deben garantizar que ningún ciudadano sea objeto de agresiones o arbitrariedades sobre este derecho.

La constitución vigente del Ecuador, regula el tema dentro del título "derechos de libertad", al reconocer «el derecho al honor y al buen nombre. La ley protegerá la imagen y la voz de la persona» (art. 66.18). Por lo tanto, en el Ecuador existe este derecho y los mecanismos apropiados para su protección en caso de que una persona se sienta desprotegida. Analizaremos ahora la evolución constitucional histórica de este derecho.

\section{REGULACIÓN CONSTITUCIONAL}

Como vimos, la Revolución Francesa y la Declaración Universal de los Derechos Humanos fueron hitos importantes en la evolución de las normas constitucionales hoy vigentes. También lo fue para el Ecuador.

Según los ecuatorianos Fernando Dobronski y Guillermo Segarra (1999, t. II, p. 15), los escritores del siglo XVIII se basaron en la concepción iusnaturalista de que el texto de la constitución debería estar íntimamente relacionado con lo expuesto en el "contrato social" de Jean Jacques Rousseau, para que adquiera un significado formal.

Así se dejó de lado la norma consuetudinaria dando preferencia al derecho positivo para la elaboración de constituciones formales, cuya 
influencia que nació de Francia a raíz de su revolución, expandió esta idea de sentar por escrito las normas fundamentales para regular el derecho de los ciudadanos además del funcionamiento y organización del Estado en sus distintos poderes.

La Revolución Francesa y la independencia de los Estados Unidos, resonarían en Quito el 10 de agosto de 1809, donde la Junta Soberana conformada por distintos ciudadanos quiteños emprendió el inicio del proceso de emancipación de Latinoamérica. Dicha junta declaró que el reino de Quito estaba desligado del Virreinato y por ende de España. Los eventos culminarían con la independencia. El primer texto Grancolombiano (expedido ya en 1821) señaló lo siguiente:

Art. 157.- «La libertad que tienen los ciudadanos de reclamar sus derechos ante los depositarios de la autoridad pública, con la moderación y respecto debidos, en ningún tiempo será impedida ni limitada.

Todos por el contrario deberán hallar un remedio pronto y seguro, con arreglo a las leyes de las injurias y daños que sufrieren en sus personas, en sus propiedades en su honor y estimación».

Esta disposición fue sumamente importante en la época en que fue expedida, pues respaldaba a los ciudadanos de la Gran Colombia en su reputación y preveía la reparación debida en caso de daño. Se concedía este derecho a su honor, estima y propiedades, lo cual garantizaba un trato justo, cordial y sobre todo respetuoso entre ciudadanos.

Pero el ideal de Simón Bolívar de mantener una nación unida y fuerte, no se cumpliría. El 13 de mayo de 1830, en el Distrito del Sur se tomó la decisión de conformar una nueva república y así surgió el Ecuador como estado soberano. La Asamblea redactó y expidió la primera Constitución, que en nuestro tema implicó un cierto retroceso a lo previsto en la constitución grancolombiana. Al respecto incluía como atribuciones del Congreso la de «conceder premios y recompensas personales por grandes servicios a la patria, y decretar honores a la memoria de los grandes servicios a la patria, y decretar honores a la memoria de los grandes hombres» (art. 26.4). En la primera carta, el honor era una condecoración otorgada por el Congreso a quienes prestaron servicios a la patria y además a su memoria, pero no destacaba su calidad moral y de dignidad que tenían los ciudadanos. Esto representaría una falta de protección a su dignidad humana; quizá existía un tema consuetudinario de respeto entre semejantes que posiblemente no hacía necesario que se estipularé en la constitución.

Posteriormente, en la constitución de 1845 se dice que los derechos de ciudadanía se pierden «por admitir empleo o condecoración de un gobierno extranjero, sin especial permiso del Congreso» (art. 10.3). En este momento 
histórico ya que rompía el paradigma colonial español, y el honor empieza a abrirse a un aspecto más general hacía la sociedad en ese entonces; sin embargo, aún no era considerado un derecho fundamental.

En los años 1851 y 1852 se expidieron otras Constituciones Políticas, que conservaban las disposiciones expuestas en la carta de 1845. Como novedad se estipuló que «todo ecuatoriano tiene derecho a conservar su buena reputación mientras no se les declare delincuente conforme a las leyes» (1851, art. 120; 1852, art. 115). No se habla expresamente del honor, pero se menciona a la reputación (que constituye una característica esencial para su aplicación, debido a que mientras no exista una declaración expresa hacia una determinada persona por el cometimiento de un delito, esta era honorable ante la sociedad). La virtud era importante para que la sociedad reconozca a una persona con calidad moral intachable; quien era catalogado como delincuente obtenía el repudio colectivo y era marginado por ser una persona que tenía calidad deshonrosa en su accionar.

Estas disposiciones se mantendrían vigentes en las reformas de las constituciones de 1861, 1869 y 1878, donde se vincularía el honor con la buena reputación, siempre que la persona no cometiera un delito que lo declare delincuente, las condecoraciones seguían en manos del Congreso y se prohíban las distinciones hereditarias. Los honores a nivel jerárquico y militar eran de suma importancia porque representaban una imagen a nivel estatal, y esto conllevaba a que la reputación de un país no se viese comprometida si el honor concedido fuera del país de origen, implicaba algún tipo de traición. Aquí recordamos lo que Kelsen (2016, p. 13) decía:

«(...) existe otra convicción moral, la que afirma que el valor supremo es el interés y el honor de la nación. Por lo tanto, cuantos sigan esta teoría están obligados a sacrificar su vida y a matar en caso de guerra a los enemigos de la nación, cuando los intereses de ésta así lo requieran (...)»

Con esta afirmación, se valora la responsabilidad que tenía una persona respecto de su país de origen al momento de recibir una condecoración que pudiese repercutir a esferas internacionales. Por este motivo el Congreso se reservaba el derecho de conceder o no aquellos títulos a favor de determinadas personas para analizar si perjudicaban o no la imagen del país. Esta disposición constitucional se mantuvo vigente durante mucho tiempo.

Avanzando en la evolución del honor, la Constitución Política de 1884 presentó un progreso significativo. Al respecto señaló: «todos pueden expresar libremente sus pensamientos de palabra o por la prensa, respetando la Religión, la decencia, la moral y la honra, y sujetándose, en estos casos, a la responsabilidad legal» (art. 28). Cincuenta y cuatro años después de que 
el Ecuador se constituyera como República, el honor ya no solamente se centraba en condecorar a quienes sirvieron a la patria; ahora los ciudadanos estaban amparados en su calidad y dignidad humana con respecto a sus semejantes. Esta disposición marca el punto de partida de lo que será el derecho a la imagen y buena reputación, ya que salvaguarda el honor de las personas, frente a opiniones emitidas no solo de carácter personal, también por la prensa, haciendo énfasis en el respeto.

En las Constituciones de 1897 y 1906 se mantiene el principio de inocencia vinculado al honor, como estaba tipificado en 1884 (cfr. carta de 1897, art. 29; carta de 1906, Art. 26.2). Una persona honorable era aquel del cual la sociedad no necesitaba preocuparse, porque se entendía que sus actos estaban acorde a la ley, moral y buenas costumbres de la sociedad; caso contrario la persona merecía repudio por alterar el orden social.

Más adelante, en el año de 1929 se expidió otra constitución donde hemos de destacar ciertos avances. Esta carta decía:

Art. 151.- «La Constitución garantiza a los habitantes del Ecuador, principalmente, los siguientes derechos: (...) 3. El derecho de ser presumido inocente y de conservar honor y buena reputación, mientras no haya declaración de culpabilidad, conforme a las leyes.

Nadie puede ser obligado a prestar testimonio en juicio criminal o de policía, contra si mismo ni contra su consorte, ascendientes, descendientes o colaterales, hasta el cuarto grado civil de consanguinidad o segundo de afinidad, ni compelido con juramento por medio de apremios, a declarar contra sí mismo, en asuntos que acarreen responsabilidad penal; (...)

12. La libertad de opinión de palabra, por escrito, por la prensa, por medio de dibujo o de cualquiera otra manera. La injuria y la calumnia, en cualquier forma y toda manifestación de carácter notoriamente inmoral, estarán sujetas a responsabilidad legal».

Como se ve, el honor quedaba estrechamente ligado a la presunción de inocencia: la buena reputación se conservaba mientras no se pruebe lo contrario. Además constaba la clásica prohibición expresa de obligar a prestar testimonio culpable contra uno mismo, contra los familiares. Por otra parte, esta constitución ya estipulaba el mecanismo de protección ante una opinión de mala fe o arbitraria que constituya injuria o calumnia, es decir, que atente contra el honor de las personas. El derecho al honor y buena reputación ya no solamente constaba como una enunciación de derechos fundamentales de los ecuatorianos, sino que incluye además una disposición concordante que ayuda a crear un mecanismo de reparación cuando exista una afectación a este derecho, lo cual refuerza la calidad humana que tenían las personas en las relaciones con sus semejantes. 
Posteriormente, con la expedición de una nueva constitución de 1945, se da otro avance, una reforma sutil que parecería no tendría tanta repercusión, pero que cambia el paradigma en la regulación. Esta carta dice:

Art. 141.- «El Estado garantiza: (...) 3. El ser presumido inocente y conservar la honra y la buena reputación, mientras no haya declaración judicial de responsabilidad conforme a las leyes.

Nadie puede ser obligado a prestar testimonio en juicio penal contra su cónyuge o sus parientes dentro del cuarto grado de consanguinidad o segundo de afinidad, ni compelido, con juramento o por medio de apremio, a declarar contra si mismo en asuntos que comporten responsabilidad penal.

Prohíbense las penas infamantes; (...)

10. La libertad de opinión, cualesquiera que fueren los medios de expresarla o difundirla.

La injuria, la calumnia y toda manifestación inmoral, están sujetas a las responsabilidades de ley.

La ley regulará el ejercicio del periodismo, tomando en cuenta que éste tiene por objeto primordial la defensa de los intereses nacionales y constituye un servicio social acreedor al respeto y apoyo del Estado. Establecerá también los medios de hacer efectivas las responsabilidades en que incurrieren los periodistas.

Ninguna autoridad podrá suspender o clausurar periódicos ni, por delitos de prensa, secuestrar imprentas o incautar publicaciones. Tampoco se perseguirá o encarcelará, bajo pretexto de tales delitos, a los redactores, colaboradores, expendedores, voceadores y demás trabajadores de la prensa, a menos que se demuestre la responsabilidad de ellos en forma legal.

Toda persona, natural o jurídica, tiene derecho, en la forma que la ley determine, la rectificación gratuita de las aseveraciones o imputaciones falsas o calumniosas hechas por la prensa, por la radio o por cualquier otro medio de publicidad.

Esta rectificación deberá hacerse en el mismo órgano en que se hicieran las imputaciones».

El texto refuerza notablemente el tema de las injurias y además el ejercicio del periodismo para evitar posibles abusos que puedan cometerse al momento de transmitir la información a la ciudadanía, además de regular mejor la reparación inmediata y de forma gratuita en caso de haber injuriado con sus comentarios, ya no solo a las personas naturales, sino que también incluye a las personas jurídicas. Un detalle a ser considerado es el que se encuentra en el numeral 3: aquí aparece por primera vez de manera explícita la honra como derecho fundamental a ser protegido, aunque se deja de lado al honor. Parecería que esto no tiene implicaciones directas porque ambos términos son considerados sinónimos, aunque según lo antes visto honor y honra tienen significados distintos y por lo tanto su protección implica efectos diferentes. Aquí se protege un derecho más específico, la virtud y estimación con la cual un ser humano es digno de formar parte en una 
sociedad; por lo tanto la defensa de este derecho va directamente hacia la dignidad humana personal, lo cual explica por qué fue regulada de forma extensiva para garantizar su protección y resarcimiento en caso de daños o arbitrariedades producidos en contra de este derecho.

Al año siguiente se expidió otra constitución. En la carta de 1946 se derogaron los mencionados avances relacionados con la honra, aunque se mantuvo la vinculación del honor con la presunción de inocencia (1946, art. 187.2), lo cual implicó un retroceso en la regulación de este derecho. No se explican las razones para este cambio.

Posteriormente, la Constitución de 1967 dice:

Art. 28. «Derechos garantizados.- Sin perjuicio de otros derechos que se deriven de la naturaleza de la persona, el Estado le garantiza: (...) 4. El derecho a la honra y a la intimidad personal y familiar. (...)

18. La libertad y seguridad personales. En consecuencia: (...) j) La inocencia se presume mientras no haya declaración judicial de culpabilidad con arreglo a la ley.

El Estado pondrá empeño en devolver la honra a quien por error judicial u otra causa hubiere sido acusado, juzgado o sentenciado».

Estas disposiciones garantistas retoman el concepto de honra e intimidad personal y familiar, aunque no de forma taxativa como estipulaba la Constitución de 1945. Con todo, constan expresamente como derechos fundamentales, lo cual mostraba que la honra era un bien jurídico protegido a favor de las personas. Sobre la presunción de inocencia aún ligada al derecho de la honra, existe un cambio importante cuando se agrega la devolución de la honra a la persona erróneamente juzgada, garantía que estaba a cargo del Estado. Según la constitución, se podía recuperar la honra cuando se hubiese demostrado la inocencia mal juzgada, lo que eventualmente podría permitir una reparación.

El año 1979, año del regreso a la democracia después de la época donde gobernó la Junta Militar, entró en vigencia una nueva Constitución. Al respecto señaló:

Art. 19.- «Toda persona goza de las siguientes garantías: (...) 3. el derecho al honor y a la buena reputación. Toda persona que fuere afectada por afirmaciones inexactas o agraviada en su honor, por publicaciones hechas por la prensa u otros medios de comunicación social, tiene derecho a que éstos hagan la rectificación correspondiente en forma gratuita».

Esta disposición recibió varios cambios, pero solo de forma, y se mantuvo vigente tanto en los textos constitucionales de 1984 y 1998. Como se ve, se garantiza el derecho al honor y la buena reputación, además de 
incluir los mecanismos de protección en caso de comentarios u opiniones inexactas o arbitrarias para su debida reparación.

Finalmente, la constitución vigente protege «el derecho al honor y al buen nombre. La ley protegerá la imagen y la voz de la persona» (art. 66.18). Además se incluye el derecho a la réplica, y la garantía jurisdiccional del habeas data, entre otros derechos relacionados con las comunicaciones. El art. 66.18 protege el honor, el nombre, la imagen y - se añade un nuevo elemento - la voz de la persona, lo que implica una garantía para que el ciudadano no sea objeto de injurias o arbitrariedades en su contra, pero además este derecho implica que sus opiniones emitidas sean con la misma exactitud y sin ningún tipo de tergiversación que pueda dañar su imagen por cualquier alteración.

En cuanto a su forma de defensa, los atentados contra el honor constituyen un delito, al tenor del Código Orgánico Integral Penal, que dice:

Art. 182.- Calumnia.- «La persona que, por cualquier medio, realice una falsa imputación de un delito en contra de otra, será sancionada con pena privativa de libertad de seis meses a dos años.

No constituyen calumnia los pronunciamientos vertidos ante autoridades, jueces y tribunales, cuando las imputaciones se hubieren hecho en razón de la defensa de la causa.

No será responsable de calumnias quien probare la veracidad de las imputaciones. Sin embargo, en ningún caso se admitirá prueba sobre la imputación de un delito que hubiere sido objeto de una sentencia ratificatoria de la inocencia del procesado, de sobreseimiento o archivo.

No habrá lugar a responsabilidad penal si el autor de calumnias, se retractare voluntariamente antes de proferirse sentencia ejecutoriada, siempre que la publicación de la retractación se haga a costa del responsable, se cumpla en el mismo medio y con las mismas características en que se difundió la imputación. La retractación no constituye una forma de aceptación de culpabilidad».

El artículo solamente hace referencia a la falsa imputación que una persona hace a otra se refiere a un delito y no a una opinión vertida en general que pudiere ocasionar alguna difamación en contra de la persona perjudicada, lo cual nos lleva a reflexionar que penalmente el mecanismo para defender el honor de un ciudadano sería insuficiente. Esto parecería quedar hoy como contravención de cuarta clase, según el artículo 396.1. En todo caso, el mismo código prevé como delitos o contravenciones algunas otras conductas relacionadas con el tema (cfr. arts. 394.2, 584, 627, etc.).

En el ámbito civil, el Código Civil señala que «las imputaciones injuriosas contra la honra o el crédito de una persona dan derecho para demandar indemnización pecuniaria, no sólo si se prueba daño emergente o lucro cesante, sino también perjuicio moral» (art. 2231). En cierto sentido, 
la vía civil demuestra mayor eficacia jurídica y procesal para poder exigir el resarcimiento al perjuicio causado en contra del honor, la buena reputación, imagen y voz de la persona agraviada, tal como la constitución estipula. Estos derechos evolucionaron en cada época, según vimos líneas atrás.

\section{JURISPRUDENCIA}

Una vez analizada la configuración histórica del derecho constitucional al honor, honra y buena reputación, vemos cómo se han garantizado estos derechos. Antes de ver algunos casos, vale recordar que el Ecuador suscribió y ratificó la Convención Americana de Derechos Humanos mediante Decreto en 1984. El documento reconoce lo siguiente:

Artículo 11. «Protección de la Honra y de la Dignidad

1. Toda persona tiene derecho al respeto de su honra y al reconocimiento de su dignidad.

2. Nadie puede ser objeto de injerencias arbitrarias o abusivas en su vida privada, en la de su familia, en su domicilio o en su correspondencia, ni de ataques ilegales a su honra o reputación.

3. Toda persona tiene derecho a la protección de la ley contra esas injerencias o esos ataques.»

Se ratifica así la importancia del derecho al honor, honra y buena reputación de las personas. Pero el reconocimiento general también requiere la reglamentación concreta para establecer el alcance de estos derechos. La Corte Constitucional en Sentencia, en la acción de inconstitucionalidad 04715-SIN-CC, afirmó:

«De acuerdo a la norma de derecho internacional, el derecho al honor, entonces, se fundamenta en el reconocimiento de la dignidad de las personas, al igual que la prohibición de cualquier intromisión, sea por parte de agente privado o público, dentro de la vida personal; ni ataques que puedan afectar la honra individual o colectiva.

Así, cuando un individuo se considere afectado en su reputación o dignidad, tiene el derecho, de conformidad con los artículos 75 de la Constitución de la República, 4 y 8 de la Convención Americana de Derechos Humanos, de acceder a la justicia y mecanismos judiciales idóneos que permitan la pronta reparación del derecho vulnerado. Es decir, el Estado deberá garantizar el acceso efectivo a mecanismos judiciales idóneos que permitan la reparación del derecho, entre ellos el derecho penal.

En otras palabras, al verse vulnerado el derecho al honor de un individuo, el afectado tiene el derecho de acudir a la justicia para someter esta controversia a que sea resuelta por los jueces pertinentes quienes realizarán sus actuaciones con apego al marco constitucional y legal vigente, a efectos de precautelar la seguridad jurídica». 
Esta opinión es importante porque, como se resaltó, este derecho tiene sus limitaciones, y puede afectar la calidad de una persona en determinados ámbitos, al nivel que su reparación se embarque en las esferas civiles y penales, dependiendo de la gravedad del daño causado. La misma sentencia señala que:

«(...) el derecho al honor y buen nombre constituye un limitante a la libertad de expresión en cualquiera de sus formas, ya que este último no puede ser ejercido de tal manera que afecte negativamente otros derechos constitucionales; por tanto, la libertad de expresión no es un derecho absoluto y debe ser interpretado en su integralidad con los demás derechos establecidos en el texto constitucional con el objetivo de que este sea ejercido de manera adecuada sin afectar la honra de terceras personas.»

Esto implica que el derecho al honor es derivativo de otros derechos y se encuentra ligado a los mismos, como es el caso del derecho a la libertad de expresión, que si bien brinda la potestad a las personas de opinar libremente respecto de cualquier tema, situación o persona, no puede exceder al nivel de atentar contra la dignidad de las personas y causar perjuicios a su imagen, con el pretexto de invocar su planteamiento sin escrúpulo alguno. La afirmación es recogida por Soto Gama (2010, p. 99), quien afirma:

«La limitación a este derecho supone la prohibición de la publicación y emisión de injurias en contra de cualquier persona y por cualquier medio. Las limitaciones también inciden sobre las informaciones difamatorias y el correspondiente delito de difamación. En ocasiones, este delito es el instrumento de que se valen los funcionarios públicos para acallar críticas u ocultar conductas ilícitas».

Lo dicho concuerda con lo señalado por la Primera Sala de lo Penal de la Corte Nacional de Justicia (Casación por injuria, 2009), la cual manifiesta que en un Estado Constitucional de Derecho, la intervención penal en la esfera de libertad, solo se justifica de manera excepcional; el derecho penal es la última ratio, la última opción de una sociedad para proteger bienes jurídicos. Esto requiere la tipicidad debida del delito de injuria, y el concurso del dolo, según se indica:

«El elemento subjetivo del tipo exige la presencia del dolo en el caso de los delitos que, como el de la injuria, tengan una naturaleza que excluye la forma culposa de comisión. El dolo entendido de manera general como concurrencia de los elementos cognitivo y volitivo, esto es conocimiento y voluntad, en el caso específico de la injuria, expresa este segundo elemento como la intención o ánimo de menoscabar claramente el honor y reputación de la persona humana Esto es a lo que animus injuriandi, el cual queda excluido en el presente caso, por resultar 
evidente el ánimo de información y denuncia que motiva al señor Fausto Lupera Martínez, quien solicita se investiguen supuestas irregularidades, lo cual no puede ser considerado como lesivo contra la honra, como bien jurídicamente protegido por el tipo penal de la injuria».

En cuanto al honor se refiere, esto implica que la materialidad del daño debe existir como elemento de perjuicio personal; también ha de darse el dolo, la acción positiva de causar daño.

Con la evolución de la sociedad es conveniente ampliar estos criterios para abarcar otras esferas. Respecto al derecho de honor, honra y buena reputación, existen nuevas alternativas de perjuicio gracias a las nuevas tecnologías y a la publicidad masiva de la información, que requieren mecanismos adecuados de protección. La Corte Constitucional en Sentencia 048-13-SEP-CC al respecto dice:

«La dignidad de la persona, limita el derecho a la libertad de expresión reconociendo los denominados derechos de la personalidad: el derecho al honor, a la intimidad y a la propia imagen. El derecho al honor alude, desde una vertiente personal, a la conciencia que uno tiene de su propia dignidad moral, a la autoestima. Desde una perspectiva social el derecho al honor sería la imagen que los demás tienen de nosotros, esto es, la reputación, buen nombre o fama que uno tiene ante los demás. La violación de este derecho al honor ocurre cuando públicamente se imputa a una persona hechos falsos que menoscaban su reputación o atentan contra su autoestima. Por ejemplo, se considera que Miguel infringe el derecho al honor de Pedro si Miguel divulga públicamente que Pedro ha sido infiel a su esposa o que ha sido condenado por asesinato y estas imputaciones son falaces».

Por este motivo es importante delimitar los derechos individuales, ya que estos terminan donde inicia el derecho colectivo. Además, en cuanto al reconocimiento y aplicación de estos derechos, no existe distinción alguna ya que todas las personas son iguales ante la ley sin importar su religión, etnia, pensamiento, inclinaciones sexuales, ideología política entre otros. La misma sentencia lo expone citando a Larrea Holguín:

«El honor es un bien inmaterial, que se asocia al concepto de dignidad humana, que consiste en el buen nombre que tiene una persona por su comportamiento individual y social. Hay un honor interno o subjetivo que es el valor asignado a su personalidad, en sus distintos aspectos: moral, profesional, social, etcétera, por el propio sujeto; y un honor objetivo o externo que es el que le atribuyen los demás para valorarlo. Ambos aspectos son objeto de protección legal tanto en el ámbito del Derecho Civil como del Derecho Penal.

Los sujetos protegidos por el derecho al honor son todos los seres humanos, y no solo aquellos que revistan el carácter de ejemplares e intachables». 
La Corte Constitucional ha aclarado que el derecho al honor, honra y buena reputación se refiere a las personas naturales, no a las personas jurídicas. Esto tiene su razón de ser, porque desde que inició la civilización, el ser humano fue consciente que sus actos tienen repercusiones en determinada sociedad donde se desempeña, y por ello se debió limitar su accionar para evitar perjuicios contra sus semejantes; pero las personas jurídicas tienen otros mecanismos para hacer valer su reputación; su personería es una ficción legal que tiene existencia jurídica por ley. Son las personas que están dentro de estas instituciones los sujetos de protección de este derecho en su calidad de seres humanos.

Según la Sentencia 282-13-JP/19 §31 de la Corte Constitucional:

«Toda vez que el fundamento de la noción de derechos es la dignidad de las personas, es claro para esta Corte Constitucional que la titularidad de los derechos recae en los individuos o colectivos, mas no en el Estado y sus distintos órganos, que son los llamados a respetar, proteger y garantizar tales derechos. Ahora bien, esto no obsta que, a fin de garantizar un ejercicio de defensa en igualdad de condiciones en los procedimientos de carácter administrativo y judicial, se reconozca la aplicación de las garantías del debido proceso para todas las personas naturales y jurídicas, incluso las de derecho público».

Y, en lo que respecta al derecho del honor, honra y buena reputación, el $\S 35$ dice:

«Dada su íntima vinculación con la dignidad, el Estado no puede ser titular de tales derechos. Por el contrario, es el llamado a respetarlos y protegerlos. Distinto podría ser el caso en el que un funcionario público, como persona natural, busque la protección de su derecho al honor. Es indiscutible que los funcionarios públicos son sujetos del derecho constitucional al honor, en tanto ese derecho es inherente a la dignidad humana24. Sin embargo, el Estado, sus órganos e instituciones, con o sin personalidad jurídica, no son sujetos del derecho al honor; en consecuencia, éste no podría verse afectado por la difusión de información u opiniones emitidas en ejercicio del derecho a la libertad de expresión».

El Estado, como institución, carece de la titularidad del derecho al honor pero en cambio está llamado a tutelarlo y respetarlo conforme lo establece la Constitución, los tratados internacionales y las demás leyes nacionales. Esto está de acuerdo con la doctrina extranjera. Por ejemplo, Francisco de la Torre (2017, p. 61) ha afirmado:

«Honor e intimidad, de la imagen que, en su rango constitucional, solo se predica de la persona física (sin perjuicio de emergente significado de una imagen corporativa y del frecuente debate derivado, más que de la titularidad, del choque entre la imagen de la persona individual y de la persona jurídica, cuando se sugiere la utilización de aquella para ésta (procediendo la grabación de una cajera de 
supermercado para prevenir o demostrar la sustracción o la grabación de unos trabajadores para impulsar la marca de una fábrica de electrodomésticos)».

Todos los seres humanos desde que inician su existencia son sujetos de derechos por el solo hecho de formar parte de la especie humana. Ello les otorga igual libertad y dignidad en la sociedad, sobre todo ante la ley. Esto también implica la solidaridad y el respeto de estos derechos con sus semejantes, condición de posibilidad de un comportamiento fraterno y de una correcta convivencia social.

\section{CONCLUSIONES}

Del análisis hecho, se extraen las siguientes conclusiones:

1. El derecho al honor, la honra y buena reputación ha estado presente en la historia de la humanidad pero se ha aplicado de distinta manera en cada época. Este es un atributo necesario para la correcta convivencia entre las personas.

2. A lo largo de la historia constitucional del Ecuador, el derecho fundamental al honor y la honra han tenido diferentes conceptualizaciones, dependiendo del momento histórico en el que se regulaba. En algunos casos existía avances en su tutela, como ocurre en la Constitución Política de 1945 que tenía mecanismos de tutela efectiva para salvaguardar este derecho. Desde la conformación de la República ecuatoriana en 1830, tuvieron que pasar 54 años para que el derecho al honor sea concebido y ampliado, no circunscrito a la aceptación del Congreso que reconocía títulos o méritos a determinadas personas.

3. Toda persona tiene la obligación de respetar y el derecho a que los demás le respeten tanto en su honor y honra, considerando también los valores que subyacen de estas cualidades como son la honestidad, honradez, buena fama, buena reputación, dignidad humana, etc. Este derecho se menoscaba con actos de humillación, maltrato e insultos, los cuales contravienen todos estos valores, atentan contra la moral y contra las buenas costumbres de la sociedad, y tienen como base el dolo.

4. El derecho al honor y la honra si bien son sinónimos a nivel jurídico, tienen alcance distinto. El primero es una cualidad general, que otorga buena fama o reputación que una persona tiene en base a sus aportes y méritos en la sociedad, mientras que el segundo tiene un carácter subjetivo, ya que se relaciona con las virtudes que el ser humano posee y con las cuales actúa frente a una colectividad. 
5. Ecuador reconoce al derecho de honor, honra y buena reputación no solamente a nivel constitucional, también es suscriptor de tratados internacionales en materia de derechos humanos que buscan tutelar estos derechos. Existe jurisprudencia de última instancia y constitucional que delimita su alcance.

6. El derecho al honor, honra y buena reputación deriva de otros derechos, como el de libertad de expresión. Este derecho delimita su alcance, ya que, si bien brinda la potestad a las personas de opinar libremente respecto de cualquier tema, situación o persona, no justifica atentar contra la dignidad de las personas y causar perjuicios a su imagen.

7. En cuanto a la jurisprudencia constitucional, la Corte Constitucional ha señalado que son las personas naturales las resguardadas por este derecho, porque solo los seres humanos son sujetos de derechos y obligaciones sin distinción alguna, susceptibles de cometer errores o faltas hacia sus semejantes; esto no es aplicable a las personas jurídicas (incluida entre ellas el Estado), ya que al ser ficciones legales carecen de calidad humana para ser sujetos de estos derecho, aunque no obsta que tengan la obligación de respetar, proteger y tutelarlos en debida forma.

8. La evolución de la sociedad obliga a que los mecanismos de tutela efectiva de estos derechos se adapten a las circunstancias del nuevo contexto tecnológico. 


\section{REFERENCIAS}

Büschges, C. (1997). Las Leyes del Honor "Honor y estratificación social en el Distrito de la Audiencia de Quito". Revista de Indias, 209, pp. 55-84.

Cabanellas de Torres, G. (2003). Diccionario Jurídico Elemental. Buenos Aires: Heliasta.

Corte Interamericana de Derechos Humanos, Comisión Nacional de los Derechos Humanos. (XI-2018). Documentos Básicos en materia de Derechos Humanos en el Sistema Interamericano. Organización de los Estados Americanos.

De la Torre Olide, F. (2017). Extensión del derecho al honor a los entes con y sin personalidad jurídica en un escenario digitalizado. En V. Cazurro Barahona (ed.), Derecho Digital (pp. 59-82). Barcelona: Bosch.

Dipietro, A. (2012). Manual de Derecho Romano, 4a ed. Buenos Aires: Ed. Buenos Aires.

Dobronski Ojeda, F. \& Segarra Íñiguez, G. (1999). Historia del Ecuador "El camino del Sol”, t. I y II. Quito: Gráficas Mediavilla Hnos.

Ecuador, Codificación de la Constitución Política de la República del Ecuador. Registro Oficial 2 de 13-II-1997.

Ecuador, Codificación de la Constitución Política de la República del Ecuador. Registro Oficial 763 de 12-VI-1984.

Ecuador, Código Civil. Registro Oficial Suplemento 46 de 24-VI-2005.

Ecuador, Código Orgánico Integral Penal. Registro Oficial Suplemento 180 de 10-II2014.

Ecuador, Constitución de la República del Ecuador. Diario de la Convención Nacional de 3-XII-1845.

Ecuador, Constitución de la República del Ecuador. Diario de la Convención Nacional de 25-II-1851.

Ecuador, Constitución de la República del Ecuador. Diario de la Convención Nacional de 6-IX-1852.

Ecuador, Constitución de la República del Ecuador. Diario de la Convención Nacional de $8-\mathrm{V}-1861$.

Ecuador, Constitución de la República del Ecuador. Diario de la Convención Nacional de 28-VII-1869.

Ecuador, Constitución de la República del Ecuador. Diario de la Convención Nacional de 31-III-1878.

Ecuador, Constitución de la República del Ecuador. Diario de la Convención Nacional de 4-II-1884.

Ecuador, Constitución de la República del Ecuador. Diario de la Convención Nacional de 14-I-1897.

Ecuador, Constitución de la República. Registro Oficial Suplemento 449 de 20-X-2008. 
Ecuador, Constitución del Estado del Ecuador en la República de Colombia. Diario de la Convención Nacional de 14-VI-1830.

Ecuador, Constitución Política de la República del Ecuador Codificada. Registro Oficial 969 de 18-VI-1996.

Ecuador, Constitución Política de la República del Ecuador. Registro Oficial 138 de 26III-1929.

Ecuador, Constitución Política de la República del Ecuador. Registro Oficial 228 de 06III-1945.

Ecuador, Constitución Política de la República del Ecuador. Registro Oficial 262 de 24XII-1906.

Ecuador, Constitución Política de la República del Ecuador. Registro Oficial 773 de 31XII-1946.

Ecuador, Constitución Política de la República del Ecuador. Registro Oficial 800 de 27III-1979.

Ecuador, Constitución Política del Estado Ecuatoriano. Registro Oficial 133 de 25-V1967.

Ecuador, Corte Constitucional del Ecuador. Sentencia 282-13-JP/19 de 4-IX-2019.

Ecuador, Corte Constitucional del Ecuador. Sentencia 047-15-SIN-CC de 23-IX-2015.

Ecuador, Corte Constitucional. Sentencia 048-13-SEP-CC de 31-VII-2013.

Ecuador, Corte Nacional de Justicia Primera Sala de lo Penal. Casación por injuria de 1VI-2009, Gaceta Judicial. Año CX. Serie XVIII.

Ecuador, Sentencia 762-2009. Registro Oficial de 10-IV-2013.

Francia, Asamblea Nacional Francesa (1789). Declaración de los Derechos del Hombre y del Ciudadano. En https://www.conseilconstitutionnel.fr/sites/default/files/as/root/bank_mm/espagnol/es_ddhc.pdf.

Gran Colombia. Constitución Política Grancolombiana. Registro Auténtico 1821 de 1-I1821.

Kelsen, H. (25-IV-2016). ¿Qué es la Justicia? Revista Pensamiento Penal. En http://www.pensamientopenal.com.ar/doctrina/43295-es-justicia.

Mena Villamar, C. (2001). Lecciones de historia del Derecho, 3a. ed. Quito: Universidad Central del Ecuador.

Montesquieu, C. L. (1906). Del Espíritu de las Leyes. En http://fama2.us.es/fde/ocr/2006/espirituDeLasLeyesT1.pdf.

Naciones Unidas. (10-XII-1948). Declaración Universal de Derechos Humanos.

Ossorio, M. (2004). Diccionario de Ciencias Jurídicas, Políticas y Sociales. Guatemala: Datascan.

Soto Gama, D. (2010). Principios Generales del Derecho a la Información. Toluca: Instituto de Transparencia y Acceso a la Información Pública. 